\title{
Survey of community mental health teams
}

\author{
Natasha Mauthner, Simon Naji and Jill Mollison
}

\begin{abstract}
Aims and method The aim of the study was to describe community mental health teams (CMHTs) working in Scotland. Interviews, a focus group, and a postal questionnaire survey of identifled CMHTs were carried out.

Results Of the 53 teams identified, 42 (79\%) completed questionnaires. The average team size was 11 people. Community psychiatric nurses were in all teams, social workers and psychiatrists were in most, but psychologists were in only half. Needs assessments occurred in only $17 \%$ of teams. Fifty-one per cent of teams had open referral systems, and $38 \%$ of referrals comprised people with long-term mental health problems. Fifteen per cent of referrals were considered by teams to be inappropriate.

Clinical implications Ambiguities about appropriate structures, patient groups and interprofessional and inter-agency working require further consideration and evaluation if CMHT care is to be optimally effective.
\end{abstract}

\section{The study}

The aim was to describe community health teams (CMHTs) working in Scotland. Stage 1 comprised interviews and a focus group with purchasers and providers (Table 1) from health boards, trusts and CMHTs within the Borders, Grampian and Greater Glasgow Health Board areas. These elicited detailed information about the development and operation of CMHTs, and informed the content of the questionnaire used in Stage 2.

Table 1 Key informants

\begin{tabular}{lr}
\hline Job title & $\mathbf{n}$ \\
\hline Consultant psychiatrist & 3 \\
Clinical psychologist & 3 \\
Community psychiatric nurse & 3 \\
Consultant in public health & 2 \\
Hospltal general manager & 1 \\
Clinical director & 1 \\
Service performance manager & 1 \\
Total & 14 \\
\hline
\end{tabular}

Stage 2 comprised a questionnaire survey of all identified CMHTs in Scotland. The questionnaire was developed from existing research (in particular Onyett et al (1994)), and from stage 1 of the study. Teams were included if they: (a) were formally recognised as a multi-disciplinary team by purchasers and providers; (b) served adults with mental health problems as the primary client group; (c) did not offer specialist services only for people within any specific restricted group.

Within each of the 15 Scottish health board areas, an individual responsible for community mental health, either at the board or at relevant trusts, was contacted by telephone to find out how many teams there were and to identify someone who could liaise with them. In areas with teams, questionnaires and explanatory letters were sent to the liaison person. In areas without teams, a second telephone interview with the initial contact was undertaken to ascertain why CMHTs had not been implemented; and establish whether there were plans to implement CMHTs.

Table 2 Number of community mental health teams in the 15 health board areas in Scotland, and numbers of questionnaires returned

\begin{tabular}{lcc}
\hline Health board areas & $\begin{array}{c}\text { Number of } \\
\text { teams }\end{array}$ & $\begin{array}{l}\text { Number of } \\
\text { questionnaires } \\
\text { retumed (\%) }\end{array}$ \\
\hline Argyll and Clyde & 0 & 0 \\
Ayrshire and Arran & 6 & $5(83)$ \\
Borders & 4 & $4(100)$ \\
Dumfries and Galloway & 0 & 0 \\
Fife & 0 & 0 \\
Forth Valley & 3 & $3(100)$ \\
Grampian & 16 & $14(88)$ \\
Greater Glasgow & 10 & $7(70)$ \\
Highland & 3 & $1(33)$ \\
Lanarkshire & 6 & $6(100)$ \\
Lothian & 4 & $1(25)$ \\
Orkney & 0 & 0 \\
Shetland & 1 & $1(100)$ \\
Tayside & 0 & 0 \\
Western Isles & 0 & 0 \\
Total & 53 & $42(79)$ \\
\hline
\end{tabular}




\section{Findings}

A total of 53 CMHTs were identified in nine health boards: six health board areas did not have CMHTs (Table 2). Each CMHT received a questionnaire, and $42(79 \%)$ were returned completed. The six areas without CMHTs reported that although forms of multi-disciplinary working were in place, these were not regarded as formal CMHTs. Reasons for the absence of formal CMHTs included lack of resources and infrastructure, opposition from clinicians (general practitioners (GPs)) and satisfaction with current practice. Four of these areas planned to implement teams, in at least three cases by April 1997. The other two areas had no such plans.

Team size, composition and location

The median (interquartile range throughout) team size (number of people) was 11 (9-17.7). In terms of full-time equivalents (FTEs), the median was 7.7 (5.4-12.7).

Community psychiatric nurses (CPNs) were present in all teams (Table 3 ). The next most frequent discipline was consultant psychiatrist $(90 \%)$, followed by social worker $(81 \%)$, occupational therapist $(81 \%)$, and doctor other than consultant psychiatrist (76\%). Clinical psychologists were represented in only $55 \%$ of teams. Disciplines other than those listed were present in $11(26 \%)$ of teams, the most frequent categories being pharmacist, physiotherapist and social work assistant.

Table 3 also shows the median FTEs for each discipline, which most closely reflects the relative contribution of each to team working. The contribution of CPNs was at least twice that of any other discipline. Consultant psychiatrists, although present in most teams, had a half-time commitment, as did clinical psychologists (who are much fewer in number). The median number of people joining teams over the previous year was $3(1-4)$. The median number of people leaving teams over the previous year was 1 $(0.75-2)$, indicating that team size is increasing. Thirty-two $(76 \%)$ teams had a dedicated office for administrative work. Of these, 16 (52\%) were based in community health centres or community resource centres. Seven (22\%) teams had an office base within a hospital in-patient unit. Eight teams (25\%) were based at other types of site, including medical centres, hospital out-patient units, nursing homes and general office blocks.

\section{Catchment area and population}

Forty teams (95\%) had a catchment area, the median size of which was 80 square miles (15543 square miles). Twenty-five $(62.5 \%)$ of these teams were aligned to general practices, whereas $15(37.5 \%)$ were aligned to geographical localities. The median size of population served by teams was 47000 (30000-80000). The median number of GPs with whom the teams worked was 27 (20-54).

Only $7(17 \%)$ teams reported that there had been a formal assessment of the mental health needs of the population served by the team. Where needs assessment had been undertaken, it had most often been by the health board or the relevant trust.

Table 3 Team composition

\begin{tabular}{|c|c|c|c|c|}
\hline Discipline & $\begin{array}{l}\text { Teams containing } \\
\text { discipline, } n(\%)\end{array}$ & $\begin{array}{l}\text { Median input per } \\
\text { team FTEs (people) }\end{array}$ & $\begin{array}{l}\text { Interquartile range ! } \\
\text { FTEs (people) }\end{array}$ & $\begin{array}{l}\text { Median ratio of FTEs } \\
\text { to people in teams }\end{array}$ \\
\hline Community psychiatric nurses & $42(100)$ & $2(3)$ & $1-4(2-4)$ & 1 \\
\hline Consultant psychiatrists & $38(90)$ & $1(1)$ & $0.5-1(1-2)$ & 0.5 \\
\hline Social workers & $34(81)$ & $1(1)$ & $0.5-1.4(1-2)$ & 0.8 \\
\hline Occupational therapists & 34 (81) & $1(1)$ & $0.5-1(1-2)$ & 1 \\
\hline Doctors (other than consultants) & $32(76)$ & $1(2)$ & $0.5-1.5(1-2)$ & 0.8 \\
\hline $\begin{array}{l}\text { Administrative staff (including } \\
\text { receptionists) }\end{array}$ & $31(74)$ & $1(1.5)$ & $1-2(1-2.25)$ & 0.9 \\
\hline Clinical psychologists & $23(55)$ & $0.6(1)$ & $0.4-1(0-1)$ & 0.5 \\
\hline $\begin{array}{l}\text { Nurses (other than community } \\
\text { psychiatric nurses) }\end{array}$ & 18 (43) & $1(1)$ & $0-5(0-5)$ & 1 \\
\hline $\begin{array}{l}\text { Generic mental health workers } \\
\text { or support workers }\end{array}$ & $8(19)$ & $0(0)$ & $0-0.8(0-1)$ & 0.9 \\
\hline Other specialist therapists & $4(10)$ & $0(0)$ & $0-0.5(0-0.5)$ & 0.6 \\
\hline Others & 11 (26) & $0.1(0)$ & $0-0.5(0-1)$ & 0.5 \\
\hline Volunteer staff & 0 & & & \\
\hline
\end{tabular}

FTE, full-time equivalents. 


\section{Referrals}

Teams had been taking referrals for a median period of three years (1.25-4.75 years). Twentyone $(50 \%)$ teams had formal criteria for referral. The teams operated one of two referral systems. Twenty-one (51\%) teams had open systems, accepting referrals from any member of the community, health and social services staff, police, relatives, friends or self referrals. Twenty (49\%) teams had a closed or restricted system, accepting referrals only from pre-defined sources. The most frequent sources were GPs $(85 \%)$, psychiatric and general hospital staff $(35 \%)$, social services $(30 \%)$, self- or relative referral (15\%), primary care teams $(10 \%)$ and consultant psychiatrists (10\%). Two teams specifically indicated that they did not accept self- or relative referrals.

Twenty-two (52\%) teams indicated that referrals could be directly to an individual within the team. In $34(81 \%)$ teams, referrals were made to the team and not to an individual. In 17 (41\%), referrals could be made both to the team or to individuals within the team.

The median number of referrals received each month was $34(20-62)$ and the median number of clients discharged from the team each month was 20 (15-30), indicating a rapidly expanding case load. There was a significant positive correlation between the number of referrals per month and size of the team, both in terms of people (Spearman's $r=0.53, P<0.001$ ), and FTEs $(r=0.50, P<0.01)$. Number of referrals was not associated with type of referral system. Twentythree $(55 \%)$ teams stated that they offered the first point of contact for all adult mental health referrals in the locality. This was not significantly associated with the type of referral system or numbers of referrals received.

Teams were asked to indicate what percentage of referrals represented severe and long-term mental health problems. (Severity was defined as a level of distress or disturbance that might result in a diagnosis of psychosis (e.g. schizophrenia), psychiatric admission, or intensive community-based interventions to prevent admission. 'Long-term' problems were defined as those requiring intensive service use over a period of six months or more.)

The median proportion of referrals to the team defined as severe and long-term mental health problems was $38 \%(20-40)$. The most common types of referrals not falling into this category were: social or situational problems and crises, alcohol and drug problems, marital and other relationship problems, and brief minor affective states. There was no significant association with size of team, type of referral system or whether the team offered the first point of contact.
The median proportion of referrals considered to be inappropriate was $10 \%(5-15)$. The most common categories of inappropriate referrals included mild to moderate depression or anxiety, situational/social crises, relationship difficulties, and bereavement, although many others were also mentioned. There was no significant association with type of referral system, or number of referrals received.

Twenty-one (50\%) teams pooled all referrals for assessment before allocation for assessment, 9 (21\%) teams pooled some of their referrals, and 12 teams $(29 \%)$ did not pool referrals. There was no association between pooling and size of team. case load composition, type of referral system or number of referrals.

\section{Clinical activities}

Thirty-eight $(90 \%)$ teams met at least once a week, $3(7 \%)$ teams met once every two weeks, and one team met once a month. Twenty-one (50\%) teams met at an in-patient unit and 12 (29\%) at a community mental health centre. The remaining teams mentioned a range of other sites, including the CMHT base, a consultant psychiatrist out-patient clinic, a consultant psychiatrist office or other hospital space, a community hospital, and a social work department.

Respondents were asked to indicate whether each of 13 facilities or activities was provided by the team (Table 4). Very high proportions of

Table 4 Percentage of teams offering carerelated facilities

\begin{tabular}{|c|c|}
\hline Services & $\begin{array}{l}\text { Number (\%) } \\
\text { undertaking }\end{array}$ \\
\hline $\begin{array}{l}\text { Multi-disciplinary direct work with clients } \\
\text { following assessment }\end{array}$ & $42(100)$ \\
\hline $\begin{array}{l}\text { Consultation to mental health workers } \\
\text { from other agencles }\end{array}$ & 40 (95) \\
\hline $\begin{array}{l}\text { Multi-disciplinary assessment, two or more } \\
\text { different disciplines at the same time }\end{array}$ & $36(86)$ \\
\hline $\begin{array}{l}\text { Continuing professional development for } \\
\text { team members }\end{array}$ & 36 (86) \\
\hline Promotion of self-help & $34(81)$ \\
\hline $\begin{array}{l}\text { Clinical supervision of team members' } \\
\text { work }\end{array}$ & 33 (79) \\
\hline Individual service planning & $32(76)$ \\
\hline Development of team working skills & 31 (74) \\
\hline $\begin{array}{l}\text { Public education (e.g. on preventing } \\
\text { mental problems) }\end{array}$ & 31 (74) \\
\hline $\begin{array}{l}\text { Publicising the service (1.e. more than } \\
\text { just word of mouth) }\end{array}$ & $26(62)$ \\
\hline $\begin{array}{l}\text { Physical space for outside agencies } \\
\text { to use }\end{array}$ & $16(38)$ \\
\hline $\begin{array}{l}\text { Client access to team members after } \\
\text { working hours and at weekends }\end{array}$ & $16(38)$ \\
\hline Drop-in/walk-in/open access facility & $13(31)$ \\
\hline
\end{tabular}


Table 5 Percentage of teams offering care-related services or referring for these services

\begin{tabular}{|c|c|c|c|}
\hline Services & $\begin{array}{l}\text { Number (\%) } \\
\text { undertaking }\end{array}$ & $\begin{array}{l}\text { Number (\%) } \\
\text { referring }\end{array}$ & $\begin{array}{l}\text { Service } \\
\text { unavailable }\end{array}$ \\
\hline $\begin{array}{l}\text { Services particularly for people with severe and long-term } \\
\text { mental health problems }\end{array}$ & $40(95)$ & $2(5)$ & \\
\hline $\begin{array}{l}\text { Assessment of activities of daily living (e.g. money, personal } \\
\text { hygiene) }\end{array}$ & $40(95)$ & 1 (2.5) & $1(2.5)$ \\
\hline Support/education for carers & $40(95)$ & $1(2.5)$ & $1(2.5)$ \\
\hline Therapy or counselling for individuals & $39(95)$ & $1(2.5)$ & $1(2.5)$ \\
\hline Formal assessments under the Mental Health Act & $38(90)$ & $3(7)$ & 1 (2) \\
\hline Drug treatments (other than depot clinics) & $33(80)$ & $6(15)$ & $2(5)$ \\
\hline Training in activities of daily living & 33 (79) & $8(19)$ & 1 (2) \\
\hline Immediate in vitro response to crisis & $31(74)$ & $3(7)$ & 8 (19) \\
\hline $\begin{array}{l}\text { Practical 'hands-on' help with day-to-day problems } \\
\text { (e.g. shopping, transport) }\end{array}$ & $30(71)$ & $11(26)$ & $1(2)$ \\
\hline Therapy or counselling for families & $29(71)$ & $9(22)$ & $3(7)$ \\
\hline Group therapy & $23(55)$ & $16(38)$ & 3 (7) \\
\hline Depot clinics & $21(50)$ & $10(24)$ & $11(26)$ \\
\hline $\begin{array}{l}\text { Services particularly for people who have never used } \\
\text { mental health services before }\end{array}$ & 20 (48) & 5 (12) & $16(38)$ \\
\hline $\begin{array}{l}\text { Direct purchase of services by practitioners or case } \\
\text { managers controlling budgets }\end{array}$ & $15(36)$ & $6(15)$ & 20 (49) \\
\hline Accommodation & $14(54)$ & 20 (49) & $7(17)$ \\
\hline $\begin{array}{l}\text { Services for people whose behaviours services find } \\
\text { 'challenging' or 'difficult to manage' }\end{array}$ & $14(35)$ & $11(27)$ & $15(38)$ \\
\hline Services particularly for women & $12(29)$ & $10(24)$ & 20 (48) \\
\hline Day care or other occupation & $10(25)$ & $26(65)$ & $4(10)$ \\
\hline Work opportunities & $7(17)$ & $27(64)$ & $8(19)$ \\
\hline Services particularly for people from specific ethnic groups & & $10(25)$ & $30(75)$ \\
\hline
\end{tabular}

Table 6 Service user and community member involvement

\begin{tabular}{llll}
\hline Level of involvement & $\begin{array}{l}\text { Already } \\
\text { implemented } \\
n \text { (\%) }\end{array}$ & $\begin{array}{l}\text { Plan to implement } \\
\text { in next } 6 \text { months } \\
n(\%)\end{array}$ & $\begin{array}{l}\text { No plans to } \\
\text { implement } \\
n \text { (\%) }\end{array}$ \\
\hline $\begin{array}{l}\text { Regular surveys or collection of information on user } \\
\text { views (beyond individual case work) }\end{array}$ & $22(52)$ & $6(14)$ & $13(31)$ \\
$\begin{array}{l}\text { Routine user attendance at service management/ } \\
\text { steering group or business meeting with users having } \\
\text { an advisory role }\end{array}$ & $6(14)$ & $9(21)$ & $26(62)$ \\
$\begin{array}{l}\text { Routine user attendance at service management/ } \\
\text { steering group or business meeting with users having } \\
\text { a decision-making role }\end{array}$ & 0 & $7(17)$ & $34(81)$ \\
$\begin{array}{l}\text { Routine community member attendance in service } \\
\text { management/steering group or business meeting } \\
\text { with members having an advisory role }\end{array}$ & $5(12)$ & $5(12)$ & $31(74)$ \\
$\begin{array}{l}\text { Routine community member attendance in service } \\
\text { management/steering group or business meeting } \\
\text { with members having a decision-making role }\end{array}$ & $3(7)$ & $4(9)$ & $33(79)$ \\
\hline
\end{tabular}

teams were providing a range of clinical, consulting and team development activities. However, fewer than $40 \%$ provided access to team members outside normal working hours, or open-access to the community.

Respondents were also asked to indicate whether each of 20 further activities was undertaken directly by the team, referred on to another service, or whether the activity was unavallable locally (Table 5). Given the composition and perceived remit of CMHTs, it is not surprising that the large majority of teams were providing services for people with severe mental health problems, and undertaking assessments, a range of therapies, and other activities traditionally associated with mental health teams. It was 
notable, however, that $95 \%$ were also giving support to carers, and about $80 \%$ were offering support in 'activities of daily living' within the community.

Thirty-five (83\%) teams had direct access to hospital beds via a team member such as a psychiatrist. Five (12\%) teams had to refer outside the team to gain access to beds, and two (4\%) teams used other arrangements. In 34 $(81 \%)$ teams, responsibility for the patient was transferred to hospital staff after admission, although $17(50 \%)$ teams continued to provide care. In 8 (19\%) teams, responsibility was retained by the team.

Fourteen teams $(34 \%)$ operated a case management or care management system; 10 (24\%) did not but planned to in the next six months; and $17(41 \%)$ did not and had no such plans. In 9 $(64 \%)$ of the teams operating case or care management, it was one of a number of tasks carried out by team members. In $3(21 \%)$ teams, case or care managers took sole responsibility, and $2(14 \%)$ teams made other arrangements such as rotating responsibility. Thirty teams (71\%) operated a keyworker system other than case or care management.

Fifteen teams (36\%) participated in the care programme approach to discharges from inpatient care; $27(64 \%)$ did not, but $23(85 \%)$ of these had plans to implement the care programme approach within the following six months.

\section{Management and funding}

Twenty-two (52\%) teams undertook regular collection of users' views of the service. Of the 19 which did not, only $6(32 \%)$ planned to do so within the next six months (Table 6). Involvement of service user and community members in management activities was very low, and few teams planned to increase such involvement.

Twenty-six teams $(62 \%)$ indicated that they had a team manager or coordinator. Most commonly, the professional status of the team manager/coordinator was a nurse $(42 \%)$, followed by CPN (27\%), consultant psychiatrist (19\%), social worker (8\%) and joint CPN and social worker $(4 \%)$. Thirty-six teams $(86 \%)$ had access to administrative/clerical support. In 10 (24\%) teams, leadership/management tasks were the responsibility of one member of the team. In the remaining $31(76 \%)$ teams, there was some sharing of these tasks.

The majority of teams were funded by NHS trusts $(46 \%)$ or by health and social services $(44 \%)$, and managed by trusts $(54 \%)$ or health and social services $(36 \%)$. Only three $(7 \%)$ teams were health board funded and only $2(5 \%)$ were health board managed. One team was jointly
Table 7 Agencies undertaking formal monitoring or evaluation of the community mental health team (CMHT) work

\begin{tabular}{|c|c|}
\hline Monitoring body & No. of CMHTs \\
\hline Trust & 6 \\
\hline CMHT members & 6 \\
\hline Health board & 3 \\
\hline Audit team within trust & 2 \\
\hline $\begin{array}{l}\text { Line managers and directorate } \\
\text { management team }\end{array}$ & 2 \\
\hline Scottish health feedback & 2 \\
\hline Local university & 2 \\
\hline Managers at local and trust level & 1 \\
\hline Contracts and planning officers & 1 \\
\hline Internal audit & 1 \\
\hline Chartermark assessor & 1 \\
\hline $\begin{array}{l}\text { Joint evaluation team (health board } \\
\text { and social services senior manager) }\end{array}$ & 1 \\
\hline Audit department & 1 \\
\hline Team manager & 1 \\
\hline Quality assurance & 1 \\
\hline Patient services manager & 1 \\
\hline Contracts and information & 1 \\
\hline Independent body & 1 \\
\hline $\begin{array}{l}\text { External joint planning structure involving } \\
\text { line management from relevant } \\
\text { disciplines and research personnel }\end{array}$ & 1 \\
\hline $\begin{array}{l}\text { Mental health directorate, quality } \\
\text { control officer and audit }\end{array}$ & 1 \\
\hline $\begin{array}{l}\text { Senvice performance manager in } \\
\text { conjunction with team members }\end{array}$ & 1 \\
\hline $\begin{array}{l}\text { Patients services manager, contract } \\
\text { information }\end{array}$ & 1 \\
\hline Medical records department & 1 \\
\hline Locality manager & 1 \\
\hline Senior charge nurse and line manager & 1 \\
\hline $\begin{array}{l}\text { Local business managers and records } \\
\text { collect activity figures }\end{array}$ & 1 \\
\hline Clinical services manager & 1 \\
\hline $\begin{array}{l}\text { Adult mental health clinical service } \\
\text { management group }\end{array}$ & 1 \\
\hline
\end{tabular}

funded by the local trust, GP locality fund, and GP research fund.

Work was formally monitored or evaluated in 26 teams (62\%). Table 7 shows the wide range of bodies undertaking this activity, and it is likely that methods and tools of evaluation also vary widely.

\section{Interview data}

The main themes to emerge from the qualitative interviews and focus group were:

(a) confusion over definitions of CMHTs;

(b) dilemmas over the client group of CMHTs;

(c) the benefits of teams despite difficulties with the team model; 
(d) factors associated with successful teams;

(e) the difficulties of 'user involvement'; and

(f) relationships between CMHTs and primary care.

These issues are considered in greater detail in the discussion below.

\section{Comment}

This section draws on the results both from the survey and from the interviews and focus group. We encountered considerable confusion about what constitutes a 'CMHT, and several professionals drew distinctions between formal CMHTs and loose 'networks' of professionals. In one region (Lothian), it was difficult to establish whether there were any CMHTs as conflicting accounts were obtained from professionals at the health board and at the trust.

\section{Dilemmas over the client group of CMHTs}

One of the central problems faced by CMHTs concerns 'gatekeeping' and targeting their service towards the severely mentally ill, in the face of the needs of a group of patients often referred to as the 'worried well'. Just over half of the patients referred to teams were said not to represent severe and long-term mental health problems. None the less, only $10 \%$ of these referrals were considered by the respondents to be 'inappropriate'. Thus, while the formal remit of the CMHTs may be to provide care for more severely ill patients, teams are operating, de facto, within a broader remit. The appropriateness of client groups was a dominant theme in the interviews. The advantages of providing for patients with milder mental health problems included reducing waiting times and financial incentives in accepting such referrals from GPs. Disadvantages included reduced resources for the care of chronic mentally ill; concerns that the 'worried well' may be seen simply because they are more vocal; and risk of burn-out for staff.

It was striking that only $17 \%$ of teams had available any formal assessment of the mental health needs of the population they served. As a result, the allocation of professionals to teams may be driven solely by availability rather than identified need (a top-down rather than a bottom-up approach), resulting in a lack of fit between needs and team resources, including composition. This may be a partial explanation of the relatively low number of clinical psychologists in teams. Similarly, some interviewees suggested that patients may be allocated to a team member on the basis of availability rather than appropriate skill. On a wide scale, this will move CMHTs towards the American model of generic mental health care workers which may be contrary to the principle of multi-disciplinary team working.

On average, CMHTs had been taking referrals for about three years. During the key-informant interviews and the focus group there was widespread agreement that CMHTs and the team model provides a range of benefits to patients and professionals, including: continuity of care across hospital and community settings; easier access to services for the patient; potential prevention of admission to hospital; a more integrated provision of services; a more complex range of services in the community than patients had on long-stay hospital wards; professional interchange and support; improved relations with consultant psychiatrists; crossing of professional boundaries; increased supervision for community team members; increased communication between health professionals in a team; and professionals being associated with a particular locality and with particular practices.

Despite these benefits, respondents felt that work still needed to be done to improve CMHTs. The problems highlighted included: staffing problems; interpersonal issues; professional rtvalries; team leadership/management/coordination; insufficient team-building days; insufficient support and training for CMHT members; increased work load and paperwork for CMHT members and risk of burn-out; imbalance of case loads of different CMHTs in a given health board area; the need for clearly defined roles and responsibilities of different team members; the danger and inappropriateness of team members becoming 'generic mental health care workers'; insufficient provision of community services; shortage of back-up services (e.g. psychiatric hospital beds); poor communication with GPs; the need for clear referral criteria for GPs; poor links and conflict between health, social work and voluntary organisations; focus on the development of CMHTs at the expense of the hospitals sector with consequent demoralisation of hospital staff; insufficient training in managerial skills for clinicians who become managers; lack of initial needs assessments and proper resource calculations for allocation of professionals to teams; idea of patient participation still needs to be fully realised; and methods of addressing the needs of patients with less severe mental health problems.

The success of teams was felt to depend on a range of variables including: adequate resources; commitment of health professionals, especially GPs; good working relationships, especially between consultant psychiatrists and others; secretarial/administrative support; coordinated strategy from health boards and trusts; an approach to organisation and operation of teams based on clinical need rather than resourcedriven; a clear remit, including appropriate client groups; and team building initiatives. 
The relationship with primary care in general, and GPs in particular, was considered to be critical to the success of CMHTs and the team model. Critical factors included: interested GPs; shared operational policies; referral guidelines; and information exchange. Difficulties in the relationship between CMHTs and GPs arose from: working with numbers of GPs too great for the establishment of personal relationships; inappropriate referrals; professional rivalries and disagreements over clinical responsibility between GPs and psychiatrists; and GPs imposing ways of working on teams.

User involvement was relatively infrequent. Broadly defined, it is a central element in CMHT working, but respondents reported that user involvement can pose a number of difficulties and dilemmas. In particular, it was felt that the extent to which it is possible depends upon the severity of illness, and whether the patient sees her/himself as ill. It was also reported that many patients just want to be taken care of and do not want the responsibility of involvement in care decisions. There was also some concern that vocal users may be unrepresentative.

The Care Programme Approach (CPA) is designed to ensure that a programme of care be developed for the complex health and social needs of all patients with long-term mental health problems, and involving professionals from different disciplines and agencies. Despite the fact that CPA was introduced in Scotland in 1992 , only $36 \%$ of teams were participating in it. Although most of the rest had plans to implement CPA, there was widespread concern over the lack of supporting resources.

\section{Discussion}

Although there is some uniformity among CMHTs in Scotland, they are more accurately described as varying widely in all aspects of their operation. Given the lack of formal guidance about optimum team structures and models of working, and the underlying paucity of researchbased evidence about CMHTs, it is not surprising either that there is widespread variation or that those involved in the development and operation of teams are having to discover problems and seek solutions in an ad hoc fashion.

This study has highlighted a number of issues which would benefit from further research. (a) What is the appropriate 'skill-mix' for CMHTs?

(b) How do CMHTs combine generic mental health workers with the appropriate provision of specialist services?

(c) How effective are the lines of communication between professionals within and beyond CMHTs?

(d) What are the advantages and disadvantages of CMHTs being aligned to general practices or geographic areas?

(e) What are the advantages and disadvantages, for users and professionals, of open and closed referral systems?

(f) What types of patients are most likely to benefit from CMHT care?

(g) What are the advantages and disadvantages, for users and professionals, of an 'out of hours' CMHT service?

(h) What are the most appropriate means and methods of monitoring and evaluating CMHT care?

(i) How effective and efficient is CMHT care?

\section{Acknowledgements}

We express our gratitude to Steve Onyett and colleagues who helped us to construct the questionnaire, and to all those who completed it. The Health Services Research Unit is funded by the Chief Scientist Office of the Scottish Office Department of Health which also funded the survey. The opinions expressed, however, are those of the authors.

\section{Reference}

ONYETT, S., HEPPLESTON, T. \& BUSHNELL, D. (1994) A national survey of community mental health teams. Joumal of Mental Health, 3, 175-194.

Natasha Mauthner, Research Fellow, Research Unit in Health and Behavioural Change, Department of Public Health Sciences, University of Edinburgh; *Simon Naji, Programme Director, and Jill Mollison, Statistician, Health Services Research Unit, University of Aberdeen, Drew Kay Wing, Polwarth Building, Foresterhill, Aberdeen AB25 2ZD

*Correspondence 